\title{
CORRECTION
}

View Article Online

View Journal I View Issue

D) Check for updates

Cite this: RSC Adv., 2020, 10, 24242

\section{Correction: Magnetic mesoporous bioactive glass for synergetic use in bone regeneration, hyperthermia treatment, and controlled drug delivery}

\author{
Muhammad Saif Ur Rahman, ${ }^{\text {ab }}$ Muhammad Asif Tahir, ${ }^{c}$ Saima Noreen, ${ }^{c}$ \\ Muhammad Yasir, ${ }^{\mathrm{d}}$ ljaz Ahmad, ${ }^{\mathrm{e}}$ Muhammad Bilal Khan, ${ }^{\mathrm{C}}$ Khawaja Waqar Ali, ${ }^{\mathrm{f}}$ \\ Muhammad Shoaib, ${ }^{* e}$ Ali Bahadur ${ }^{* g}$ and Shahid lqbal ${ }^{\text {h }}$ \\ Correction for 'Magnetic mesoporous bioactive glass for synergetic use in bone regeneration, hyperthermia \\ treatment, and controlled drug delivery' by Muhammad Saif Ur Rahman et al., RSC Adv., 2020, 10, 21413- \\ 21419, DOI: 10.1039/C9RA09349D
}

DOI: 10.1039/dOra90069a

rsc.li/rsc-advances

The authors regret that the name of one of the authors (Khawaja Waqar Ali) was shown incorrectly in the original article. The corrected author list is as shown above.

The Royal Society of Chemistry apologises for these errors and any consequent inconvenience to authors and readers.

\footnotetext{
${ }^{a}$ Zhejiang University-University of Edinburgh Institute, Zhejiang University, Haining, People's Republic of China

${ }^{b}$ Clinical Research Center, The Second Affiliated Hospital, Zhejiang University, School of Medicine, Hangzhou 310009, Zhejiang Province, China

'Department of Chemistry, University of Agriculture, Faisalabad 38000, Pakistan

${ }^{d}$ Department of Chemistry, University of Lahore, Lahore, 54770, Pakistan

${ }^{e}$ Department of Chemistry, Government Postgraduate College Samanabad Faisalabad, 38000, Pakistan. E-mail: relyables@gmail.com

${ }^{f}$ Allama Iqbal Open University, Islamabad, Pakistan

${ }^{g}$ Department of Transdisciplinary Studies, Graduate School of Convergence Science and Technology, Seoul National University, Seoul, 16229, South Korea. E-mail: alibahadur138@snu.ac.kr

${ }^{h}$ School of Chemistry and Materials Engineering, Huizhou University, Huizhou 516007, Guangdong, China
} 